\title{
SYNTHESIZING DESIGN GROUND MOTIONS FROM MICROEARTHQUAKE RECORDS
}

\author{
By Kenzo TOKI*, Tadanobu SATO** and Junji KIYONO***
}

\begin{abstract}
We here report a method for synthesizing design earthquake motions at a short epicentral distance that makes use of microearthquake records. Characteristics such as the corner frequency and flat level were analyzed from displacement spectra determined from the digitized time histories of microearthquakes. A statistical model of microearthquake motions then was constructed by applying the nonstationary second-order autoregressive moving average (AR-MA) process. The attenuation laws of the AR-MA parameters were derived from a regression analysis. A waveform that satisfied these attenuation laws was regarded as a statistical Green function. Strong earthquake motions were synthesized by superposing the statistical Green function. In order to make this superposition, a new scaling law was derived taking into account the difference of stress drop between large events and microearthquakes. Peak accelerations and response spectra of synthesized accelerograms in the region near the source were large in comparison to the values which had ever proposed.
\end{abstract}

\section{INTRODUCTION}

A main step of earthquake resistant designs is to estimate the amount of seismic input to structures. A number of discussions and studies have been reported on this factor, the results of which are reflected in existing earthquake resistant design codes.

Classical earthquake resistant designs have been based on the seismic coefficient method because of its simplicity and practicability. But, as the size of the structure increases, this method becomes unsuitable to assess the safety of a structure against a seismic environment. For important structures such as nuclear power plants, sophisticated dynamic response analyses are required. Therefore, the knowledge of the input earthquake motion to structures is indispensable.

The procedures available to determine the input earthquake motion can be classified as three methods: The first uses actual earthquake records directly as the input of ground motion. For example, the El Centro accelerograms of the Imperial Valley Earthquake (1940), the Taft records of the Kern County Earthquake (1952) and the Hachinohe records of the Tokachi-Oki Earthquake (1968) are used frequently. The second method assumes that the earthquake motion is the output from filters ${ }^{1)}$. This procedure has three subdivisions ; use of a system response for a white noise input, superposition of harmonic waves that have different amplitudes and different phase angles, and synthesis of earthquake motion by modeling the nonstationary spectra of earthquake motions. The third method is to synthesize earthquake motion using a fault dislocation model. In this approach, a fault rupture in an infinite or semi-infinite homogeneous elastic medium usually is modeled and analyzed by the theory of elastodynamics.

* Member of JSCE, Dr. Eng., Professor, Disaster Prevention Research Institute, Kyoto Univ. (Uji-shi, Kyoto)

** Member of JSCE, Dr. Eng., Associate Professo., ditto

*** Member of JSCE, M. Eng., Research Associate., ditto 
In the first method, it is essential to use records obtained at a site that has the same conditions as those of the site being considered. In actuality, it is very difficult to obtain such matching conditions. In the second method, a simple filter can not represent the propagation path of seismic waves from the source to the observation site. In addition, under an assumption of a point source, the effect of source extent is not considered when evaluating ground shaking. From these points of defects, the third method is the best. The rupture process on a fault plane has not been thoroughly investigated yet, and formulation of the analytical Green function in ground with an irregular profile is not so easy ; therefore, a simple, layered homogeneous ground profile usually is assumed. To overcome these defects, strong ground motion were simulated by replacing the Green function by the records of small events such as foreshocks and aftershocks that have taken place within the area of the fault plane of the mainshock ${ }^{2) .3)}$. The earthquake motion simulated by the fault model, however, does not contain the high-frequency component important for the analysis of the seismic response of structures because the dislocation theory assumes a relatively smooth rupture process on a fault of large size.

We here present a method for synthesizing ground motion for earthquake resistant designs, that uses microearthquake records. The merits of using microearthquakes are that many records can be obtained during a short observation period (about 1000 records per year in the Kinki District), that records for short epicentral distances can be obtained and that the effects of the seismic path and the soil conditions near the site are reflected in these records. We investigated the characteristics of microearthquakes that have taken place in the Kinki District and analyzed the recorded waveforms in terms of the AR-MA (autoregressive-moving average) process; then we made regression analyses of the AR-MA parameters derived from each record and developed a statistical simulation model for microearthquake motion. Simulated waveforms can be regarded as a kind of Green function. Therefore, we can apply the proposed scaling law to superpose this statistical Green function and thereby synthesize a large eartrquake motion. To examine the validity of our method for synthesizing ground motion, we compared our results with actual, observed earthquake motions.

\section{CHARACTERISTICS OF MICROEARTHQUAKES}

To investigate the seismicity of the Kinki District, the research group for earthquake prediction at Kyoto University has carried out array observations in the area. At Abuyama Station, observations were started in 1965, the telemeter system being renewed in 1975. Those microearthquake records have been stored since then as analogue data. We digitized some of these data for use in the study reported here. The locations of the observation stations and the epicenters of the microearthquakes that took place from May 1980 to December 1981 in the Kinki District are shown in Fig. 1 (a). The magnitudes were determined by Watanabe's equation ${ }^{4}$, which was calculated from the displacement amplitude, are in good agreement with $M_{J}$ (the magnitude estimated by the Meteorological Agency). The hypocentral depths of the microearthquakes projected in the A-B section in Fig. 1(a) are shown in Fig. 1(b). The depthes of these

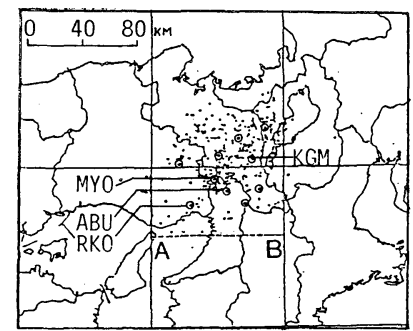

(a) Location of observation stations $(O)$ and epicenters of mecroearthquakes $(\bullet)$

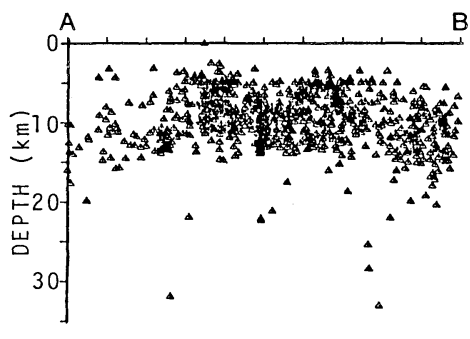

(b) Source depth

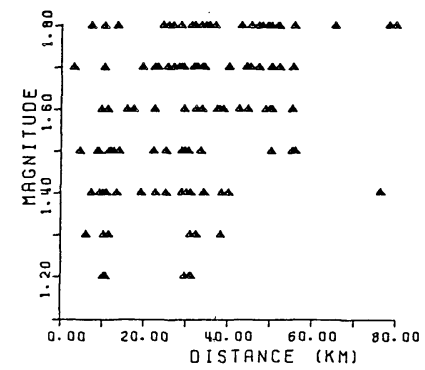

Fig. 2 Relation of the magnitudes to the epicentral distances. 
microearthquakes are distributed around ten kilometers.

Among the records, we picked up 122 records (one record, three components) at Kamigamo Station (KGM), 30 records at Abuyama Station (ABU), 30 records at Myoken Station (MYO) and 10 records at Rokko Station (RKO) as the distribution of the microearthquakes is retained in the selected data.

The relations between the magnitudes and epicentral distances are shown in Fig. 2. Epicentral distances of the selected microearthquakes range from a few kilometers to $80 \mathrm{~km}$.

A typical displacement amplitude spectrum of an observed microearthquake is shown in Fig. 3. The displacement spectrum amplitude can be divided into low- and high-frequency asymptotes. The corner frequency is defined by the intersection between the flat and decaying parts of the spectrum.

We treat only a rectangular fault plane of length $L$ and width $W$. The rupture is assumed to be initiated at a corner of the rectangle and to be propagated with a constant velocity of $V_{r}$ in all directions. If the ramp function is defined only by the final slip, $D$, and the rise time, $\tau$, then the Fourier spectrum of the displacement waveform in the far field $u(f)^{5)}$ is written

$$
u(f)=\frac{\mu R_{\theta \Phi}}{4 \pi R \rho c^{3}} D L W\left|\frac{\sin \left(2 \pi f X_{\tau}\right)}{2 \pi f X_{\tau}}\right|\left|\frac{\sin \left(2 \pi f X_{L}\right)}{2 \pi f X_{L}}\right|\left|\frac{\sin \left(2 \pi f X_{W}\right)}{2 \pi f X_{W}}\right|
$$

in which $R$ is the hypocentral distance, $\rho$ is the density, $c$ is either the $P$ or $S$ wave velocity, $\mu$ is the shear modulus and $R_{\theta \phi}$ is the radiation pattern. $X_{L}, X_{W}$ and $X_{\tau}$ are duration times associated respectively with length, width and rise time. These are given by

$$
\left.\begin{array}{l}
X_{\tau}=\tau / 2 \\
X_{L}=L / 2 V_{r} \\
X_{W}=W \cos \delta / 2 V_{s}
\end{array}\right\}
$$

in which $\delta$ is the dip angle. In a logarithmic form the spectra defined by Eq. (1) consists of four straight line asymptotes with the slopes of zero, one, two and three. The frequencies that correspond to the intersections of these straight lines are

$$
\left.\begin{array}{l}
f_{1}=1 / 2 \pi X_{L} \\
f_{2}=1 / 2 \pi X_{\tau} \\
f_{3}=1 / 2 \pi X_{W}
\end{array}\right\}
$$

Considering an earthquake motion that has a $k$ times larger $f_{1}$ value, it is evident from Eqs. (2) and (3) that $L$ is $1 / k$ times the original value. According to the scaling law (given later) , $D$ and $W$ also have a linear relation to $L\left(W=c_{1} L, D=c_{2} L\right)$; therefore, the values of $D, W$ and $L$ become $1 / k$ times. Because the seismic moment is proportional to $D W L$, it decreases $k^{3}$ times when the $f_{1}$ value increases $k$ times. Consequently, the relation between the corner frequency and the seismic moment in logarithmic form has the slope of -3 . The relation between the corner frequency and the seismic moment obtained from the microearthquakes is shown in Fig. 4. The distribution of data obtained from microearthquake records

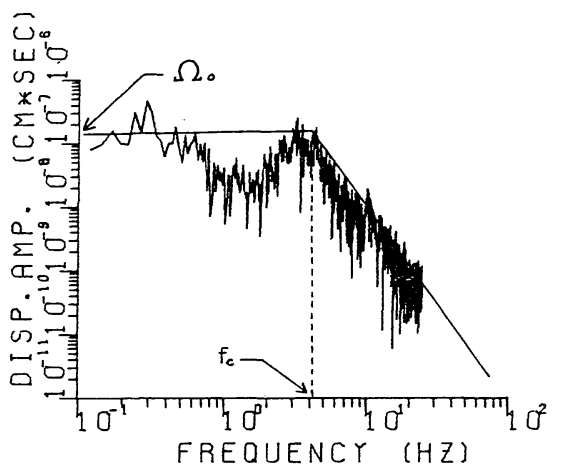

Fig. 3 Typical displacement amplitude spectrum of an observed microearhtquake.

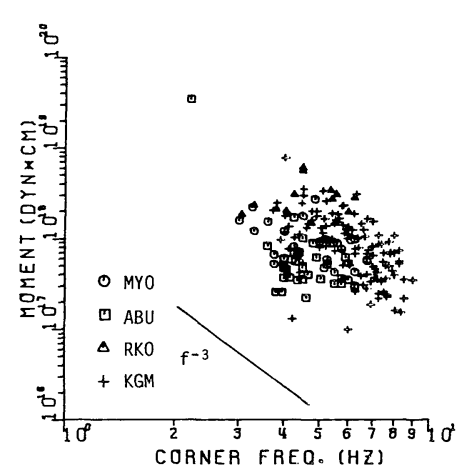

Fig. 4 Relation of the corner frequency to the seismic moment. 
has the slope of $-3 \sim-2$.

The seismic moment, $M_{0}$, is related to the amount of displacement in the low frequency region. The displacement spectrum in the low frequency region usually has a constant value, called the flat level, $\Omega_{0}$. Therefore, the seismic moment is expressed as

$$
M_{0}=\frac{\Omega_{0}}{R_{\theta \phi}}\left(4 \pi R \rho c^{3}\right)
$$

The values of $\rho$ and $c$ were chosen as $2.6 \mathrm{~g} / \mathrm{cm}^{3}$ and $3.4 \mathrm{~km} / \mathrm{s}$. The value of $R_{\theta \phi}$ was chosen 0.4 , which is the average value of $S$-wave radiation pattern.

The effective fault radius $r$ is given by considering the circular rupture ${ }^{6)}$.

$$
\left.\begin{array}{l}
r_{p}=0.21 V_{s} / f_{c p} \\
r_{s}=0.32 V_{s} / f_{c s}
\end{array}\right\}
$$

in which the rupture velocity $V_{r}$ is equal to $0.9 V_{s}, r_{p}$ and $r_{s}$ are the effective fault radii for the $P$ - and $S$-wave portions of the record and $f_{c p}$ and $f_{c s}$ are the corner frequencies for the $P$ - and $S$-wave portions. The effective fault radius, $r$, is the average of $r_{p}$ and $r_{s}$. The rise time $\tau$, can be expressed in terms of the fault area $S\left(\pi r^{2}\right)$ :

$$
\tau=\frac{16 S^{1 / 2}}{7 \pi^{3 / 2} V_{s}}
$$

and the average dislocation $D$ is given by

$$
D=\frac{16}{7 \pi \mu} r \Delta \sigma
$$

The relation between the seismic moment and the average dislocation is written

$$
M_{0}=\mu D S=\mu D \cdot \pi r^{2}
$$

Substituting Eq. ( 7 ) in Eq. ( 8 ) and solving for $\Delta \sigma$, the stress drop is given by

$$
\Delta \sigma=\frac{7 M_{0}}{16 r^{3}}
$$

By these equations, Madariaga ${ }^{6)}$, Brune ${ }^{7)}$ and Marion ${ }^{8)}$ determined many fault radii and stress drops of microearthquakes. The relations between the seismic moments, $M_{0}$, and the stress drops calculated from Eqs. (4) and (9) are shown in Fig. 5 which includes the plots for large earthquake records (O) given by Geller $^{5)}$ as well as those for the microearthquakes recorded at Kamigamo (+), Abuyama $(\bigcirc)$, Myoken $\square)$ and Rokko $(\triangle)$.

The average stress drops of the large earthquakes are hundreds of times larger than those of the microearthquakes. For earthquakes of relatively large magnitude, stress drops usually are of the order of several tens of bars regardless of the scale of the earthquake. The stress drops of microearthquakes, however, differ considerably from those of large earthquakes.

\section{STATISTICAL GREEN FUNCTION OBTAINED FROM MICROEARTHQUAKE RECORDS}

The autoregressive moving average (AR-MA) process was used to construct a stochastic time series model of microearthquake motion. Microearthquake motions are assumed to be synthesized by the second-order AR-MA process. This means that a synthesized motion is an output of a single degree-offreedom system excited by a nonstationary white noise, as shown in Fig. 6. Nonstationary characteristics of the filter such as the natural frequency and the damping ratio of a single degree-of-

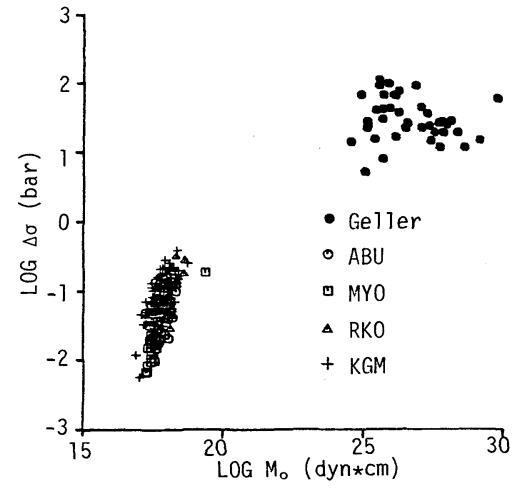

Fig. 5 Relation of the seismic moment to the stress drop.

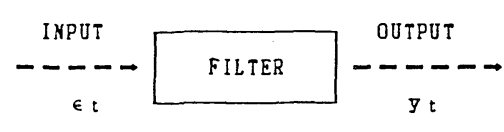

Fig. 6 Nonstationary linear filter. 
freedom system can be calculated from AR-MA parameters that are determined by the two-stage least square method ${ }^{9)}$ from a sequence of data segmenting a microearthquake record. A regression analysis then is made for these nonstationary characteristics of the filter in order to set up the attenuation law given as a function of the magnitude and hypocentral distance. The hypocentral distance is used because a microearthquake source is regarded as a point source.

The AR-MA process of order $(2,2)$ is expressed as

$y_{t}=-\alpha_{1}(t) y_{t-1}-\alpha_{2}(t) y_{t-2}+\varepsilon_{t}+\beta_{1}(t) \varepsilon_{t-1}+\beta_{2}(t) \varepsilon_{t-2}$

in which $\varepsilon_{t}$ is the input white noise ; $y_{t}$ is the observed waveform of the microearthquake; also $\alpha_{i}(t), \beta_{i}(t)(i$ $=1,2)$ are nonstationary AR-MA parameters that can be identified only from observation records if the input is assumed to be nonstationary white noise ${ }^{10)}$. Eq. (10) has a form similar to the stationary process, except that these parameters are a function of time, $t$. To make a reasonable estimate of this nonstationary trend, the rectangular time window is multiplied to a given data series and the center point of the window is assumed to be the time at which the model parameters are specified. For the window length, $1 \mathrm{~s}$ was adopted $^{11)}$.

The parameters $\alpha_{i}(t)(i=1,2)$ are related to the natural frequency and the damping of the single degree-of-freedom system as follows ${ }^{12)}$ :

$$
\left.\lambda^{2}+\alpha_{1} \lambda+\alpha_{2}=0, \begin{array}{c}
\lambda \\
\lambda^{*}
\end{array}\right\}=\exp \left(-2 \pi f_{0} h T_{m} \pm i 2 \pi f_{0} T_{m} \sqrt{1-h^{2}}\right)
$$

in which $i=\sqrt{-1}, \lambda$ and $\lambda^{*}$ are conjugate complex solutions of the quadratic equation and $T_{m}$ is the sampling interval. Using Eq. (11), we can describe the equivalent nonstationarity of the single degree-of-freedom system from nonstationary AR-MA parameters.

To construct a model with which to simulate microearthquake motions, the nonstationarities of the parameters should be expressed by simple mathematical formulas. The nonstationarities of the parameters are given in Table $1^{11)}$. In this Table, $\sigma(t)$ is input white noise intensity and $\sigma_{\max }, t_{p}$ are the maximum value of intensity and its occurrence time, respectively. The regression equations are given by

$$
P=C_{1}+C_{2} \cdot M+C_{3} \cdot \log R
$$

in which $P$ stands for the parameters in Table 1, $M$ is the magnitude and $R$ the hypocentral distance. A regression analysis was made for each parameter in Table 1 using the earthquake magnitude and the hypocentral distance.

Simulated waveforms from the obtained attenuation laws are shown in Fig. 7. The magnitude was 1.8 and the epicentral distances chosen were $10 \mathrm{~km}, 30 \mathrm{~km}$ and $50 \mathrm{~km}$. Figures (a), (b), (c) and (d) show waveforms that correspond, respecTable 1 Modeling of nonstationary parameters.

$$
\begin{aligned}
& \sigma(t)=\sigma_{\max }\left(t / t_{p}\right) \exp \left(1-t / t_{p}\right) \\
& f_{0}(t)=f_{A} \exp \left(-f_{B} t\right) \\
& h(t)=h_{A} \exp \left(h_{B} t\right) \\
& \beta_{1}(t)=\bar{\beta}_{1} \text { (const.) } \\
& \beta_{2}(t)=\bar{\beta}_{2} \text { (const.) }
\end{aligned}
$$

\section{concentrated around a $30 \mathrm{~km}$ epicentral distance, only the}

observation sites. Because records for the Rokko site were waveform at $30 \mathrm{~km}$ is showm. As the waveforms calculated by above procedure include the influence of the propagation path as well as the geological condition below the observation site, they can be considered a Green function. We call these waveforms the statistical Green function.

The waveforms have general features such that the displacement amplitude decreases and the duration of motion increases, as the epicentral distance becomes large. Because the phase of each peak in a waveform at a given station coincides at every distance, no dispersion tendency is involved in the simulations. This is because the natural frequency and damping constant do not vary greatly against the hypocentral distance.

Comparing the waveforms at each observation site, differences can be seen in the highfrequency components and the maximum amplitudes even when the magnitude and the epicentral distance are the same. This means that each site shows its inherent, peculiar vibration characteristics when excited by seismic waves. Thus, the waveform predicted at each site reflects the geological condition below the site. 


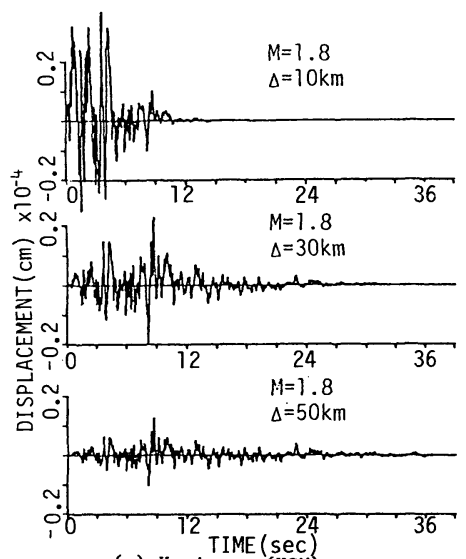

(a) Kam i gamo (KGM)

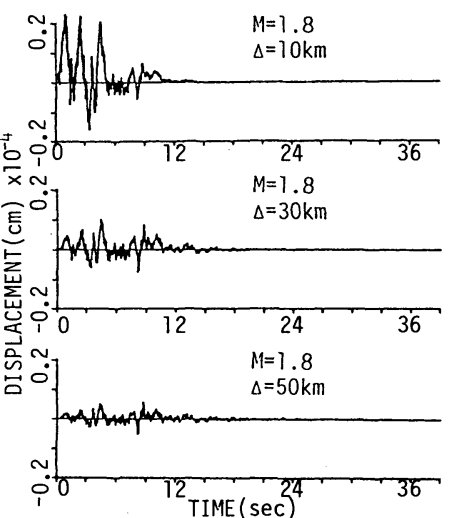

(b) Abuyama (ABU)

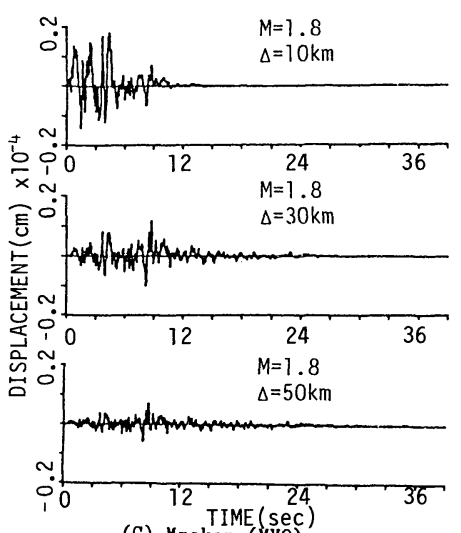

(C) MIME ( $\mathrm{sec}$
Moken (MYO)

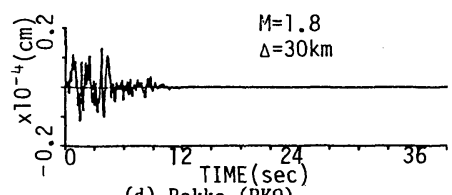

(d) Rokko (RKO)

Fig. 7 Samples of statistical Green function.

\section{SIMULATION OF SEISMIC DESIGN MOTIONS}

\section{(1) Method of Synthesis}

If the small event is given, an earthquake motion that takes into account the fault extent can be synthesized by superposing it on the assumed fault taking into account the time lags caused by the delays of rupture on the fault plane. We treat a rectangular fault plane that has the length $L$ and width $W$. Three additional parameters are needed to define the rupture mechanism of the fault; the rupture velocity, $V_{r}$, the final dislocation, $D$, and the rise time, $\tau$. This fault model is shown in Fig. 8 . The ground surface is the $X-Y$ plane, on which observation station $Q$ is located. The fault plane is on the $X-Z$ plane, and the distance from the origin of the coordinate system to the observation station $Q$ represents the source to site distance. Rupture is assumed to begin at point $A_{e}(1,1)$, propagate in all directions with uniform velocity and stop at the periphery of the fault plane.

If the fault plane is divided into $n^{2}$ elements, $n$ number of small events must occut in each element to satisfy the scaling law for rise time. We use the statistical Green function to generate these small events; but, because it does not satisfy the scaling law for stress drop, we propose a new scaling law to account for this effect in fault dislocation.

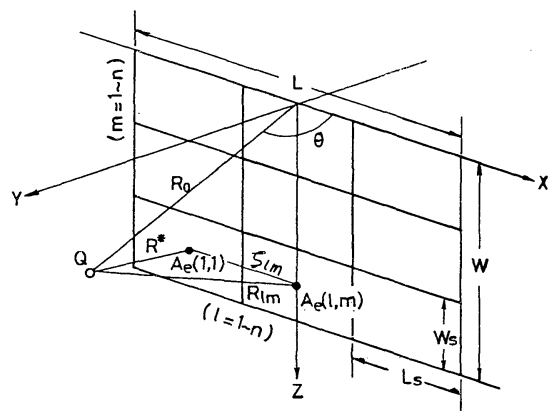

Fig. 8 Fault model.

On the basis of the scaling law, the following relation between the displacement time function of a large event, $u_{L}$, and that of a small event, $u_{s}$, can be formulated ${ }^{2)}$ :

$$
u_{L}(Q, t)=\sum_{k}^{n} \sum_{l}^{n} \sum_{m}^{n} u_{s}\left(Q, t-\tau_{k l m}\right)
$$

in which

$$
\tau_{k l m}=(k-1) \tau_{s}+\zeta_{l m} / V_{r}+\left(R_{l m}-R^{*}\right) / V_{s}
$$

Eq. (14) gives the time delay of superposition for each small event. $\tau_{s}$ is the rise time of the small event. $\zeta_{l m} / V_{r}$ is the time delay due to the rupture propagation from the point at the initial element $A_{e}(1,1)$ to the 
point at the other element $A_{e}(l, m) .\left(R_{l m}-R^{*}\right) / V_{s}$ is the time delay between the wave arriving from the initial element and the one arriving from a rupture front.

\section{(2) Scaling Law}

The statistical Green function can not be superposed directly because there is a marked difference in the stress drops between large events and microearthquakes. The stress drops of large events are several hundredfold larger than those of the microearthquakes calculated by Eq. (9).

According to the scaling law of Kanamori and Anderson ${ }^{13)}$, the ratio, $n$, between the source parameters of the large event (fault length $L$, fault width $W$ and average dislocation $D$ ) and the parameters of the small event is written in terms of the seismic moment of large event, $M_{0 L}$, and small event, $M_{0 S}$, as

$$
n=\sqrt[3]{\frac{M_{0 L}}{M_{0 S}}}
$$

A plot of the magnitude, $M_{s}$, against the logarithmic seismic moment, $M_{0}$, which is based on results obtained by Geller ${ }^{5)}$, Frankell ${ }^{14)}$ and McGarr ${ }^{15)}$, is shown in Fig. 9. The solid line is Geller's and the broken line is the results of regression analyses of the data from Frankell and McGarr and of our data.

If we use the statistical Green function for superposition, the number of $n$ in Eq. (15) becomes very large because of the substantial difference in stress drop between large events and microearthquakes. For example, although the seismic moment $M_{0}$ that corresponds to magnitude $M=6.4$ is $10^{25.29} \mathrm{dyn} \cdot \mathrm{cm}$ in Geller's expression, that of $M_{S}=1.8$ is $10^{18.7} \mathrm{dyn} \cdot \mathrm{cm}$ as seen from the broken line in Fig. 9. The value of $\mathrm{n}$ becomes 157 when these $M_{0}$ values are substituted in Eq. (15). The microearthquake records we used gave an equivalent rectangular fault length of 500-600 m, as calculated from the radius of the fault given by Eq. (5) under the assumption $L=2 \mathrm{~W}$. The estimated fault length of $M_{S}=6.4$ therefore becomes about one hundred kilometers, which is several times larger than the actual fault length. To eliminate this inconsistency, we attribute the difference in stress drop to that in dislocation. The Fourier spectrum amplitude of the statistical Green function is magnified by the ratio of the stress drops of the large event to those of the microearthquake. The waveform obtained using the inverse Fourier transformation for a magnified Green function is used as the small event for superposition.

The relations of the source parameters of the large event, small event and the statistical Green function are given in Table 2. We assume a stress drop of 30 bars for the large event and the 0.103 bar for the statistical Green function which is the average of the stress drops of all the microearthquake records. Thus, the value of $m$, which is the ratio of stress drops of large event to statistical Green function, becomes approximately 291. This means that the small event is derived from magnifying the statistical Green function by 291 .

Using these parameters, the newly defined scaling law can be written

$$
\begin{aligned}
& \Delta \sigma_{L}=\Delta \sigma_{s}=m \Delta \sigma_{S}^{*} \\
& D_{s}=m D_{S}^{*} \\
& L_{s}=L_{S}^{*} \\
& W_{s}=W_{S}^{*} \\
& M_{0 s}=m M_{0 s}^{*}
\end{aligned}
$$

From these equations

$$
\begin{aligned}
& L_{L}=n L_{S}=n L_{S}^{*} \\
& W_{L}=n W_{S}=n W_{S}^{*} \\
& D_{L}=n D_{S}=n m D_{S}^{*}
\end{aligned}
$$

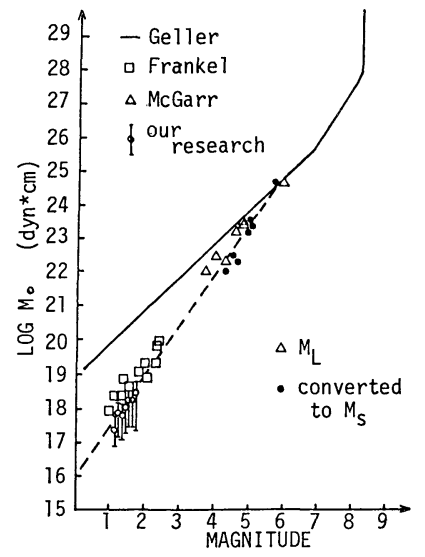

Fig. 9 Relation of the magnitude to the seismic moment.

Table 2 Source parameters.

\begin{tabular}{|c|c|c|c|c|c|}
\hline & $\begin{array}{c}\text { SEISMIC } \\
\text { MOMENT }\end{array}$ & WIDTH & LENGTH & $\begin{array}{c}\text { OISLO- } \\
\text { CATION }\end{array}$ & $\begin{array}{c}\text { STRESS } \\
\text { DROP }\end{array}$ \\
\hline $\begin{array}{c}\text { LARGE } \\
\text { EVENT }\end{array}$ & $\mathrm{Ma}$ & $\mathrm{W}_{\mathrm{L}}$ & $\mathrm{L}_{\mathrm{L}}$ & $\mathrm{D}_{\mathrm{L}}$ & $\Delta \sigma_{\mathrm{L}}$ \\
\hline $\begin{array}{c}\text { SMALL } \\
\text { EVENT }\end{array}$ & $\mathrm{M}_{\mathrm{OS}}$ & $\mathrm{W}_{\mathrm{S}}$ & $\mathrm{L}_{\mathrm{S}}$ & $\mathrm{D}_{\mathrm{S}}$ & $\Delta \sigma_{\mathrm{S}}$ \\
\hline $\begin{array}{c}\text { MICRO- } \\
\text { EARTHQ. }\end{array}$ & $\mathrm{M}_{\mathrm{OS}}^{*}$ & $\mathrm{~W}_{\mathrm{S}}^{*}$ & $\mathrm{~L}_{\mathrm{S}}^{*}$ & $\mathrm{D}_{\mathrm{S}}^{*}$ & $\Delta \sigma_{\mathrm{S}}^{*}$ \\
\hline
\end{tabular}


We get the value of superposition $\mathrm{n}$ from Eqs. $(15) \sim(17)$ by using the relation $M_{0}=\mu D L W$.

$$
n=\sqrt[3]{\frac{1}{m}\left(\frac{M_{0 L}}{M_{0 S}^{*}}\right)}
$$

Once the number $n$ is determined, the superposition of the small event is made through Eqs. (13) and (14)

\section{(3) Examination of the High Frequency Component}

The superposition procedure in the frequency domain is shown in Fig.10. If the large event is synthesized by the general scaling law without taking into account the difference of the stress drops between large events and microearthquakes, the spectrum for the statistical Green function is shifted along line A-D. The line A-D relates the corner frequency of the large event to that of the Green function. Because the spectrum in the high-frequency range has an $f^{-3}$ asymptote, the decease for the high-frequency component in this case is extreme.

However in our newly proposed scaling law, we amplified the statistical Green function hundreds of times and defined it as the small event for the purpose of superposition. The spectrum of the statistical Green function is lifted up along line A-B to compensate for the difference in stress drop between the large event and the microearthquake, then we shifted it along line $\mathrm{B}-\mathrm{C}$ which is parallel to line $\mathrm{A}-\mathrm{D}$. The shift along line B-C took into account the seismic moment ratio. Consequently, sufficient high-frequency components are involved in the simulated waveform.

When the spectrum is lifted up along line $\mathrm{A}-\mathrm{B}$, the noise also is amplified. This high-frequency noise was cut off by using the following procedure: Judging from the relation between the cut-off frequencies and the peak accelerations of the simulated waveforms, the cut-off frequency was determined just before the peak acceleration varies markedly ${ }^{16}$. The relation between the cut-off frequency and the peak acceleration is plotted in Fig. 11. The acceleration was obtained by differentiating each statistical Green function. The magnitude was 1.8 and the epicentral distance $10 \mathrm{~km}$ for the KGM, ABU and MYO stations. For the RKO station, the epicentral distance was $30 \mathrm{~km}$ as previously stated. Our results showed that the peak acceleration amplitude becomes large as the cut-off frequency increases and that there is a flat part between $15 \mathrm{~Hz}$ and $20 \mathrm{~Hz}$ at every station. We therefore chose the cut-off frequency of $15 \mathrm{~Hz}$.

\section{CONSIDERATIONS FOR MAKING A SYNTHESIZED SEISMIC DESIGN MOTION}

The modified statistical Green function was superposed by using our new scaling law to obtain a synthesized displacement waveform. Acceleration waveforms were calculated by differentiating the displacement waveforms twice. The magnitude chosen was 6.4 , the same as that of the 1971 San Fernando Earthquake. Only three epicentral distances, 10, 30 and $50 \mathrm{~km}$, were considered. The epicentral distance for Rokko, however, was only $30 \mathrm{~km}$. An example of the calculated acceleration waveforms at the KGM Station is shown in Fig. 12.

Peak accelerations for each distance at the four sites are shown in Fig. 13 along with the observed peak

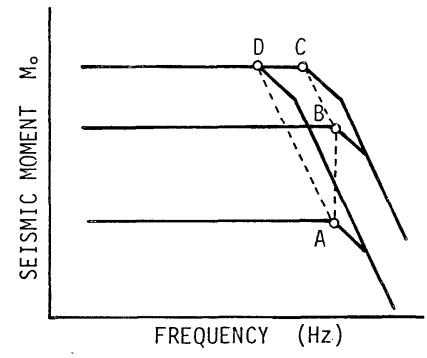

Fig. 10 Superposition procedure in the frequency domain

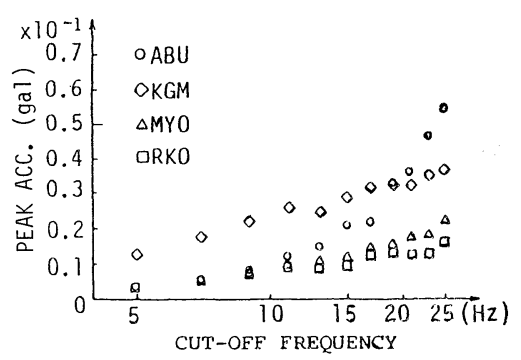

Fig. 11 Relation of the peak acceleration to the cut-off frequency. 

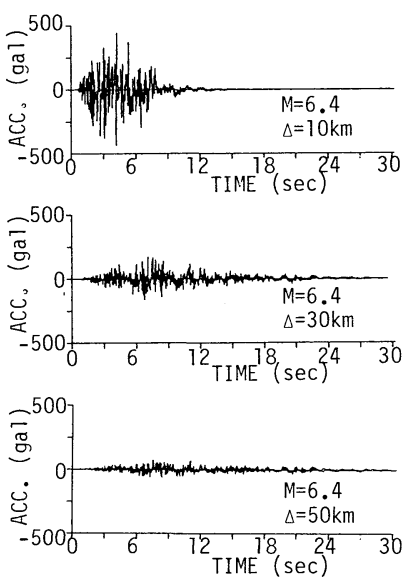

Fig. 12 Synthesized waveforms at Kamigamo (KGM).

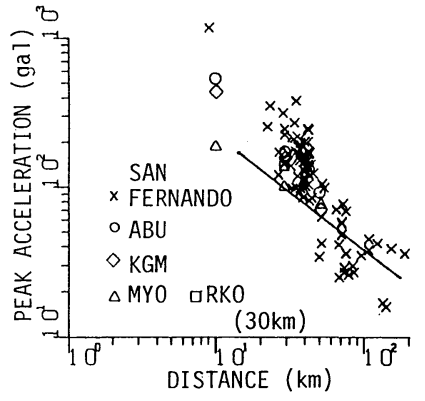

Fig. 13 Attenuation law for the peak acceleration and epicentral distance.

acceleratons during the 1971 San Fernando earthquake. The general attenuation trend for the simulated peak accelerations is similar to that for the observed accelerations, but the difference in peak acceleration at each site becomes marked as the epicentral distance shortens $(\Delta=10 \mathrm{~km})$. At these distances, the effect of the fault extent can not be neglected. This means there is difficulty in making a unique estimation of peak acceleration using the existing attenuation law. The acceleration response spectrum for epicentral distances of 10, 30 and $50 \mathrm{~km}$ at each site are shown in Fig. 14(a), (b) and (c). The damping ratio chosen was as $5 \%$ of critical. Solid lines in the response spectra were calulated from synthesized accelerograms; circles represent the spectrum proposed by Katayama et al. ${ }^{17}$. From their analysis, we chose a magnitude range of 6.1-6.7 and ranges of the epicentral distance for the two groups of 6-19 km and 20-59 km. The classification of ground is base rock. Spectral values calculated from our synthesized accelerograms are larger than those for Katayama's model, with a marked difference in the case of $10 \mathrm{~km}$. This difference might be attributed to the fact that the sensitivity for the period range around $0.1 \mathrm{~s}$ strongly decreases in SMAC accelerograph and that anaysis of katayama et al. is based on the records obtained by SMAC accelerograph. The trend is such at all sites that the spectral amplitude is higher for the short period range. Response peaks appear in the vicinity of $0.06 \sim 0.07$ and $2.0 \sim 4.0 \mathrm{~s}$. These peaks correspond to the peaks of the source spectrum which depend on the focal parameters (rise time, fault length, fault width, rupture velocity, etc. ). The predicted maximum response was $600 \sim 1500$ gal at $\Delta=$ $10 \mathrm{~km}, \quad 400 \sim 700$ gal at $\Delta=30 \mathrm{~km}$ and $200 \sim 400 \mathrm{gal}$ at $\Delta=50 \mathrm{~km}$ in the vicinity of $0.1 \sim 0.3 \mathrm{~s}$.

\section{CONCLUSIONS}

We have presented a prediction model for strong ground motion at short epicentral distances to be used to make earthquake resistant designs for civil engineering structures. The procedures and results obtained

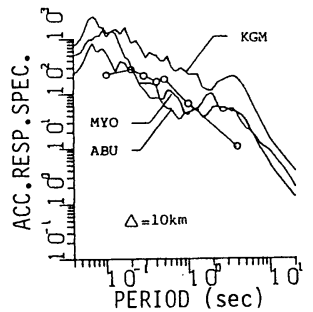

(a) $\Delta=10 \mathrm{~km}$

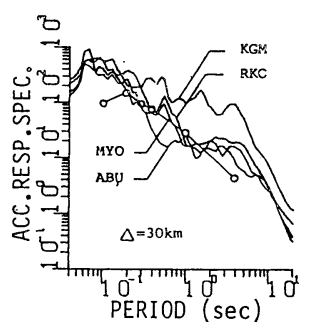

(b) $\Delta=30 \mathrm{~km}$

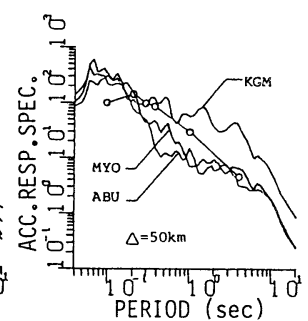

(c) $\triangle=50 \mathrm{~km}$

Fig. 14 Acceleration response spectra. 
in this study are

(1) A numerical data-base for microearthquakes that occurred in the Kinki District over an 18-month period with magnitudes between $1.2 \sim 1.8$, was constructed and the events analyzed. The microearthquakes showed tendencies of earthquake swarms, and their hypocentral depths were distributed at a depth of $10 \mathrm{~km}$. Most displacement spectra of the microearthquakes had corner frequencies at $3 \sim 9 \mathrm{~Hz}$. Spectrum amplitudes higher than the corner frequency decay at the rate of $f^{-3} \sim f^{-2}$.

( 2 ) The AR-MA process was adopted to analyze microearthquakes, and the filter characteristics of the process were detected. A regression analysis for the AR-MA parameters was made to obtain attenuation laws for the filter characteristics.

(3) The simulated waveform, based on the AR-MA process, was used as the Green function which was predicted statistically. If strong earthquake motion is synthesized using the number, $\mathrm{n}$, of Eq. (15), the fault dimension become large because the assumption of a constant stress drop regardless of the seismic scale is not valid for microearthquakes. To correct this, we have proposed a new scaling law in which the difference in the stress drop between a large earthquake and microearthquake is attributed to the difference in dislocation.

(4) To examine the property of synthesized strong earthquake motion, we compared peak acceleration amplitudes with those of the 1971 San Fernando earthquake records. The scattering of the amplitudes became small as the distance from the fault became large. Amplitudes at sites near the source, however, showed distinct differences from site to site.

( 5 ) In a comparison with the acceleration response spectrum proposed by Katayama et al., we found that the responses obtained in our study had larger values than those in Katayama's research, especially in the region near the fault.

\section{ACKNOWLEDGEMENTS}

We thank Professor H. Watanabe and all the members of the Abuyama Seismological Observatory of Kyoto University for providing the data on the microearthquakes recorded in the Kinki District.

\section{REFERENCES}

1) Shinozuka, M. and Sato, Y. : Simulation of earthquake ground motion and the response of structures, Proc. of Japan Earthquake Engineering Symposium, pp. 167 172, 1966 (in Japanese).

2) Muramatu, I. and Irikura, K. : Estimation of strong ground motion during large earthquake using observed seismograms of small events ; A Study of Predicting Damages for Large Earthquake in Tokai District, Japanese Group for the Study of Natural Disaster Science, No. A-56-3, pp. 33 46, 1981 (in Japanese).

3) Iida, M. and Hakuno, M. : The synthesis of the acceleration wave in a great earthquake by small earthquake records, Proc. Japan Soc. Civil Eng., No. 329, pp. 57 68, 1983 (in Japanese).

4) Watanabe, A. : Determination of earthquake magnitude at regional distance in and near Japan, Jishin II -24, pp. 189 200, 1971 (in Japanese).

5) Geller, R. J. : Scaling relation for earthquake source parameters and magnitudes, Bull. Seism. Soc. Am., Vol.66, No.5, pp. 1501 1523, 1976 .

6) Madariaga, R. : Dynamics of an expanding circular fault, Bull. Seism. Soc. Am., Vol. 66, No. 3, pp. 639 666, 1976.

7) Brune, J. N. : Tectonic stress and the spectra of seismic shear waves from earthquakes, J. Geophys. Res. Vol. 75, pp. 4997 5009, 1970.

8) Marion, G. E. and Long, L. T. : Microearthquake spectra in the southeastern united states, Bull. Seism. Soc. Am., Vol.70, No. 4, pp. 1037 1054, 1980.

9) Gersh, W. and Livj, R. S. Z. : Time series method for the synthesis of random vibrations systems, Jour. Appl. Mecha., pp. 159 $\sim 165,1976$.

10) Toki, K. and Sato, T. : Detections of nonstationary filtering properties of strong motion seismograms, Annuals of Disaster Prevention Research Institute, Kyoto Univ., No. 22 B-2, pp. 25 36, 1979 (in Japanese).

11) Toki, K., Sato, T. and Ejiri, J. : Simulation of strong motion seismograms by autoregressive moving average process, Annuals of Disaster Prevention Research Institute, Kyoto Univ., No.23 B-2, pp. 1 12, 1980 (in Japanese). 
12) Toki, K., Sato, T. and Oiki, Y. : Detection of dynamic properties of structural systems by the autoregressive moving average method, Annuals of Disaster Preventiong Research Institute, Kyoto Univ., No.21 B-2, pp. 57 68, 1978 (in Japanese).

13) Kanamori, H. and Anderson, D. L. : Theoretical basis of some empirical relations in seismology, Bull. Seism. Soc. Am., Vol. 65, No. 5, pp. 1073 1095, 1975.

14) Frankell, A. : Source parameters and scaling relationships of small earthquakes in the northeastern Caribbean, Bull. Seism. Soc. Am., Vol. 71, No. 4, pp. 1173 1190, 1981.

15) McGarr, A., Green, R. W.E. and Spottiswoode : Strong ground motion of Mine Tremors; Some implication for near-source ground motion parameters, Bull. Seism. Soc. Am., Vol.71, No. 1, pp. 295 319, 1981.

16) Goto, H., Kameda, H. and Sugito, M. : Correction of SMAC-B 2 accelerograph records by digital filter, Proc. of the Japan Society of Civli Engineers, No.277, pp.57 69, 1978 (in Japanese).

17) Katayama, T., Iwasaki, T. and Saeki, M. : Statistical analysis of earthquake acceleration response spectra, Prco. of the Japan Society of Civil Engeneers. No. 275, pp. 29 40, 1978 (in Japanese).

(Received March 22 1985) 